\title{
SIGNIFICACIÓN DE LA ATRIBUCIÓN DE MERCANTILIDAD A LAS SOCIEDADES ANÓNIMAS: UN COMENTARIO JURISPRUDENCIAL
}

\author{
Marcela Acuña San Martín*
}

\section{Presentación}

Del artículo $1^{\circ}$ inciso segundo de la ley 18.046 se predica que constituye una de las situaciones donde nuestro legislador comercial consagra la mercantilidad formal y no material o por objeto. Un reciente pronunciamiento de nuestra Corte Suprema permite apreciar que no existe una única interpretación jurisprudencial a aquella atribución de mercantilidad lo que no es menor, por las contrapuestas repercusiones prácticas que el asunto puede tener.

No se pretende en esta oportunidad cubrir la diversidad de cuestiones relacionadas con la mercantilidad de las sociedades, dicha misión excedería de los propósitos y características de este trabajo, muy por el contrario, este breve comentario jurisprudencial solo pretende poner en evidencia la vigencia teórica y práctica de la atribución que aquella norma realiza y algunas interpretaciones judiciales diversas que rondan el asunto.

\section{Planteamiento Preliminar}

Si bien, por regla general, conforme al artículo 2059 del Código Civil, la distinción entre sociedades civiles y mercantiles se realiza, conforme a un criterio material, esto es, atendiendo a los negocios constitutivos del objeto para el cual la sociedad se forma ${ }^{1}$, no es menos cierto que, con cada vez mayor frecuencia, el legislador huye de aquella regla y asigna una calificación sin atender al objeto material de la sociedad o empresa.

* Profesora de Derecho Comercial de la Universidad de Talca, Master en Derecho del Comercio Internacional, Correo electrónico: acunasm@utalca.cl.

Ubilla Grandi, Luis Eugenio. De las Sociedades y la EIRL Requisitos, nulidad y saneamiento. Lexis Nexis, 2003, p 11. 
Así ocurrió en el año 1981 cuando se publicó la ley 18.046 sobre Sociedades Anónimas (en adelante $\mathrm{SA})^{2}$. En ella, es determinante inciso segundo del artículo $1^{\circ}$, por cuanto, consagra la mercantilidad por mera atribución legal ${ }^{3}$, apartándose del criterio general ya referido, en efecto, señala la norma que la sociedad anónima es siempre mercantil, aún cuando se forme para la realización de negocios de carácter civil ${ }^{4}$.

Sobre la significación, en términos de consecuencias, que arroja haber hecho esa atribución no mucho se ha dicho por la doctrina nacional, principalmente por que es bastante pacífico que en materia de mercantilidad nuestro legislador en términos generales acoge una concepción objetiva. Básicamente el punto en cuestión es si la naturaleza mercantil de una sociedad, por forma $-\mathrm{y}$ vale también la pregunta para las sociedades mercantiles por objeto- mercantiliza o no todos sus actos. En otros términos, si la atribución legal de aquella determinada calidad arroja esa necesaria consecuencia o es otra la lectura que debemos dar al asunto, nótese que podríamos preguntarnos también si decir que la S.A. es siempre mercantil es equivalente a decir que es siempre comerciante y el resultado sería diverso, por cuanto no todos los actos que ejecutan los comerciantes son mercantiles.

Básicamente hay dos posiciones al respecto, la de quienes sostienen que aunque en términos generales esto significa que la SA debe ser considerada comerciante para todos los efectos en que la ley considera tal calidad, la sola circunstancia de aquel otorgamiento legal no significa que cualquier acto de ella tenga tal carácter ${ }^{5}$. Otros por el contrario, se inclinan por la mercantilización de todos los actos ejecutados por la sociedad anónima, esto es, la atribución de la naturaleza mercantil arrojaría como consecuencia la mercantilización de su actividad ${ }^{6}$ y que la sociedad, en tanto persona jurídica quedaría sujeta como consecuencia a la legislación

En la actualidad el legislador ha vuelto a utilizar el mecanismo de la comercialidad por forma y no por objeto, respecto de sujetos de reciente establecimiento. En efecto, el artículo $2^{\circ}$ de la ley 19.857 del 2003 establece que la Empresa Individual de Responsabilidad Limitada (EIRL) es siempre comercial y está sometida al Código de Comercio cualquiera que sea su objeto, pudiendo realizar toda clase de operaciones civiles y comerciales. Una norma afín se encuentra en el nuevo artículo $425 \mathrm{~N}^{\circ} 2$ del Código de Comercio, introducido por la ley 20.190 de junio del 2007, que, respecto del contenido del acto escrito de constitución de una Sociedad por Acciones (SpA), establece entre las materias que debe expresar, el objeto de la sociedad, que será siempre considerado mercantil.

3 En iguales términos el artículo 2064 del CC sustituido por el artículo 138 de la ley 18.046.

$4 \quad$ Sobre el fundamento de la mercantilidad, en nuestro medio, se ha escrito que radica en que esta sociedad recibe capital del público en general, mediante una oferta pública, formando el fondo o capital social que es dividido en acciones, razón que no compartimos, pues se olvida que no todas las SA realizan oferta pública de sus valores. Torres Zagal, Oscar. Derecho de Sociedades. Lexis Nexis, Santiago, 2006, p. 222 y ss.

5 Puelma Accorsi, Alvaro. Sociedades. Sociedad Anónima. Tomo II, $3^{\text {a }}$ edición, Editorial Jurídica de Chile, Santiago 2001, p 466. Agrega el autor que al estar mercantilizada la sociedad se deben entender comerciales y regidos supletoriamente por las normas mercantiles, los actos jurídicos internos de la sociedad como su constitución y modificación, aportes, sesiones de directorio, juntas, etc.

$6 \quad$ Román Rodríguez, Juan Pablo. Instituciones de Derecho Concursal. Lexis Nexis, Santiago 2004, p. 96 y 97. 
mercantil, debiendo cumplir con las obligaciones de todo comerciante ${ }^{7}$. Este no es un debate solo nacional, en legislaciones que han servido de antecedente a la nuestra se han planteado idénticos cuestionamientos ${ }^{8}$.

Muchos de los referidos argumentos han sido utilizados para los efectos de determinar la aplicación de las normas de quiebra a las SA, en especial, en nuestro medio, para los efectos de

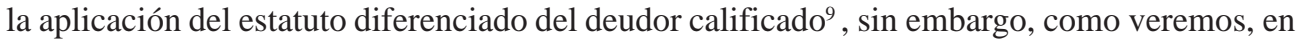
situaciones de menor notoriedad pero mayor recurrencia, el asunto puede ser igualmente determinante.

En el fallo que revisaremos la cuestión debatida consistió en determinar si una sociedad anónima por su naturaleza mercantil siempre estará afecta al pago de patente municipal, por ser el ejercicio del comercio una actividad gravada, aún cuando se haya constituido para la realización de actos que la ley no califica de comerciales, o en los hechos realice actividades puramente civiles o, no realice actividad alguna.

\section{Antecedentes del Fallo:}

La Municipalidad de Providencia cobró a "Inversiones Integradas S.A.”, sociedad cuyo giro se enmarca en la realización de toda clase de inversiones mobiliarias, inversiones inmobiliarias y la participación en empresas, la patente municipal rol No 543019 , correspondiente a los meses transcurridos entre julio de 2005 a junio de 2006 fundado en el hecho que las actividades desarrolladas constituyen un hecho gravado por la Ley de Rentas Municipales.

Con fecha 14 de septiembre de 2006, la SA solicitó al Alcalde de la Municipalidad, dejar sin efecto el giro y cobro de la patente. La Municipalidad rechazó su petición, mediante oficio $\mathrm{N}^{\mathrm{o}} 7.784$, de 27 de octubre de 2006, fundado en que las actividades que se indican en el estatuto social de la sociedad recurrente, son de aquellas que la Ley de Rentas Municipales grava con el pago de patente municipal.

Con fecha 1 de diciembre de 2006, la SA reclama la ilegalidad, en sede administrativa, recurso que fue igualmente rechazado mediante decreto exento $\mathrm{N}^{\circ} 6$, de 5 de enero de 2007 .

Torres, Derecho, cit. Nota n. 5, p 224.

Ubilla Grandi expone con bastante claridad los principales argumentos, nacionales y extranjeros, que se sostienen sobre la naturaleza comercial de la SA y la eventual mercantilización de las actividades y actos sociales. Ubilla, De las Sociedades, cit. nota n.2, p 13 y ss.

Principalmente los artículos 41 y $43 \mathrm{~N}^{\circ} 1$ del libro IV del Código de Comercio y las demás normas relacionadas que establecen un régimen más riguroso para este tipo de deudores. 
La SA interpuso, ante la Corte de Apelaciones de Santiago, reclamo de ilegalidad ${ }^{10}$ en contra de la Ilustre Municipalidad de Providencia, por el rechazo al reclamo interpuesto, señalando que el decreto alcaldicio, vulnera garantías tributarias y disposiciones constitucionales, toda vez que contraviene los artículos 6, 7 y 19 № 20 de la Constitución Política de la República, por cuanto el ente edilicio, a través de un pronunciamiento pretende que una persona jurídica quede afecta a un impuesto, sin que haya incurrido efectivamente en el hecho gravado que hace exigible el desembolso, acción que está fuera de su potestad. También vulneraría, según su alegación, el artículo 2 de la Ley sobre Bases Generales de la Administración del Estado que dispone que los órganos de administración del Estado deben someter su acción a la Constitución y a las leyes, deben actuar dentro de su competencia y no tendrán otras atribuciones que las expresamente indicadas en la ley y, finalmente, arguye que además dicho decreto vulnera los artículos 23 y 24 de la Ley de Rentas Municipales, en razón de que su representada no ha desarrollado ninguna de las actividades gravadas que se especifican en las referidas normas, por cuanto las actividades que realiza no se encuentran determinadas dentro del supuesto fáctico que configura el hecho gravado que establece la ley.

Con fecha 28 de septiembre de 2007 la Corte de Apelaciones rechazó el reclamo de ilegalidad, en razón de que el oficio $\mathrm{N}^{\mathrm{o}} 7.784$, de 27 de octubre de 2006, que dictaminaba que el recurrente se encontraba obligado al pago de la patente municipal, se encontraba ajustado a derecho.

Para estos efectos, el fallo consideró de forma decisiva lo dispuesto por el inciso segundo del artículo primero de la ley 18.046, que cita textual en el considerando $6^{\circ}$, reflexionando sobre él en los siguientes términos: Es indudable que en virtud de la norma en examen, una sociedad anónima, en términos generales, debe ser considerada comerciante para todos los efectos en que la ley considera tal calidad. De este modo, en relación a los actos y contratos que esa sociedad celebre o en que intervenga, al igual que con aquellos vinculados con el surgimiento de la misma, como acontece con el acto jurídico fundacional de toda sociedad, forzosamente habrá que concluir, que por aplicación del principio de la accesoriedad tales actos deben ser considerados como "actos de comercio". En otros términos, la sociedad anónima comercializará esos actos y contratos, particularmente aquellos realizados en su giro. Sostener lo contrario, llegaríamos a la conclusión que la norma en examen no produciría ningún efecto legal.

Bajo ese razonamiento y al encontrarse gravadas con el pago de patente municipal, entre otras actividades, el ejercicio del comercio, se concluye que una sociedad anónima por su naturaleza mercantil siempre estará afecta al pago del tributo (considerando $7^{\circ}$ ).

$10 \quad$ Ingreso N 248 2007, visto por la Tercera Sala de la Corte de Apelaciones de Santiago. 
Significación de la atribución de mercantilidad a las sociedades anónimas:

un comentario jurisprudencial.

Contra esa decisión de la Corte de Apelaciones, la SA dedujo recurso de casación en el fondo, denunciándose como infringidos los artículos 23 y 24 del decreto ley $\mathrm{N}^{\mathrm{o}} 3.063$ Ley de Rentas Municipales; el artículo $2^{\circ}$ de la Ley de Bases Generales de la Administración del Estado; los artículos $6^{\circ}, 7^{\circ}$ y $19 \mathrm{~N}^{\circ} 2,20,24$ y 26 y los artículos $32 \mathrm{~N}^{\circ} 6,63 \mathrm{~N}^{\circ} 14$ y 65 , inciso cuarto, $\mathrm{N}^{\mathrm{o}} 1$, todos de la Carta Fundamental.

La Corte Suprema, en fallo de 24 de diciembre recién pasado, rechazó el recurso de casación interpuesto ${ }^{11}$.

\section{Significación jurisprudencial de la mercantilidad de las SA}

En lo que sigue sólo daremos cuenta de las consideraciones que en torno a la mercantilidad de la SA que hicieron en el fallo, omitiendo, toda indicación a las argumentaciones y consideraciones relativas a las infracciones denunciadas que se apartan de dicha circunstancia.

En su argumentación la SA recurrente, explica, en lo que nos interesa, que su actividad se encuentra limitada sólo al rubro de inversiones (considerando $3^{\circ}$ ); que las realización de las actividades relativas al giro han sido de carácter privado o civil, es decir, inversiones pasivas, que son aquéllas que se realizan sin proyección al público o prestando servicios de inversión por los cuales percibe una determinada comisión (considerando $4^{\circ}$ ); congruente con lo anterior, señala que declaró y registró ante el Servicio de Impuestos Internos el giro de "Sociedad de Inversión y rentista de capitales" y que no ha timbrado ante ese organismo fiscalizador ningún tipo de documento tributario, esto es, facturas o boletas y siempre ha declarado "sin movimiento" (considerando $5^{\circ}$ ).

Así las cosas, según señala la recurrente, la infracción se produce porque el fallo pretende establecer la aplicación del consabido impuesto municipal a toda sociedad anónima por el solo hecho que por su constitución la sociedad se considera siempre mercantil y sin que resulte relevante si desarrolla actividades que generan renta o no, calificándolas de terciarias, lo que pugna con las normas constitucionales ya que se está estableciendo un tributo en relación a los haberes y no a las rentas (considerandos $2^{\circ}, 6^{\circ}$ y $7^{\circ}$ ).

Aunque expresamente la recurrente no se pronuncia sobre la significación de la atribución legal del carácter mercantil a las SA, queda claro, que rechaza que dicha atribución genere un efecto consecuencial tal que amerite por si y sin más el carácter comercial de las actividades por el sólo hecho de ser ella una sociedad anónima, lo que se correspondería con la primera de

11 Ingreso Rol 6799-2007 “inversiones integradas S.A. con Ilustre Municipalidad de Providencia”. Ministros Adalís Oyarzún Miranda; Fernando Castro Alamos; Haroldo Brito Cruz; Héctor Carreño Seaman; Rafael Gómez Balmaceda. En http://productos.legalpublishing.cl 
las posiciones doctrinales enunciadas más arriba y traería en este caso, la consecuencia práctica de dejar a la sociedad exenta del tributo.

A partir de ahí, encontramos en el fallo de la Corte Suprema dos interpretaciones en torno a la significación de la atribución de mercantilidad que realiza el artículo $1^{\circ}$ de la ley 18.046, una dada por las motivaciones de la decisión y la otra dada por la prevención de uno de los abogados integrantes.

\subsection{Significación contenida en la Decisión}

La Corte tuvo como hechos de la causa tanto el objeto social, que consta en el instrumento constitutivo, como la circunstancia de tener la recurrente la naturaleza jurídica de SA y, en base a ellos estimó que los jueces del fondo no incurrieron en error de derecho al decidir el rechazo del reclamo de ilegalidad.

En el penúltimo considerando y de un modo concluyente para fundar su decisión, el fallo de casación expresa: Decimocuarto: Que como se dejó establecido por la sentencia impugnada, la empresa que recurre tiene la naturaleza jurídica de sociedad anónima, lo que reviste trascendencia para resolver el asunto, toda vez que de conformidad con lo dispuesto por el inciso segundo del artículo $1^{\circ}$ de la ley $N^{\circ} 18.046$, en relación con el artículo 2.064 del Código Civil: "La sociedad anónima es siempre mercantil, aun cuando se forme para la realización de negocios de carácter civil. De ahí que, encontrándose entre otras actividades gravadas con patente municipal el ejercicio del comercio, de tal modo que una sociedad anónima por su naturaleza mercantil siempre estará afecta al pago del tributo quiere decir entonces, que la reclamante nunca ha estado en condiciones de eximirse de dicho tributo, como lo han decidido los jueces del fondo.

Para el juzgador la mercantilidad que se atribuye por ley, formalmente, a las SA imprime, como consecuencia necesaria, dicho carácter a sus actividades. Se extiende así, el manto de atribución formal que el legislador hace a la sociedad, a todas las actividades que desarrolla, extensión formal también, pues prescinde de la real naturaleza de las mismas, lo que acarrea, como consecuencia, dejar siempre a las sociedades anónimas afectas al pago de la patente, aun cuando realicen actividades civiles o más extremo aún, pese a que en los hechos no realicen actividades.

\subsection{Significación contendida en la prevención}

Ante la uniformidad de la Corte de Apelaciones y el Tribunal de Casación, sorprende la prevención de uno de los abogados integrantes, Rafael Gómez Balmaceda, quien plantea una novedosa teoría sobre la significación legal de atribución de mercantilidad a las SA lo que 
Significación de la atribución de mercantilidad a las sociedades anónimas:

un comentario jurisprudencial.

puede acarrear consecuencias prácticas muy diversas a las del fallo ${ }^{12}$. En su planteamiento se recurre a una distinción algo olvidada por la doctrina sobre sociedades, esto es, la diferenciación entre el contrato social, en tanto acuerdo de voluntades con objeto y finalidades específicos y la persona jurídica, distinta de los socios individualmente considerados, que en su virtud nace o se forma ${ }^{13}$.

En efecto, se plantea en la prevención que la sola circunstancia que una sociedad anónima esté constituida como tal y que por lo mismo deba reputarse mercantil, no significa que tenga la condición de ejercer el comercio y que por ende sea comerciante, si se considera que la mercantilidad mira al contrato y no alcanza a la persona jurídica que se forma con el contrato y que tiene por finalidad la de explotar el giro para el cual se ha creado la sociedad.

Como se aprecia, en la prevención se realiza una interesante distinción entre la naturaleza del contrato de sociedad y la naturaleza o calificación de la persona jurídica sociedad anónima, afirmando que la mercantilidad formal que se atribuye por ley afecta al contrato social, más no a la persona. En efecto, en estricto derecho que la sociedad anónima revista el carácter de ser mercantil, quiere decir que es comercial en cuanto a la índole que tiene el contrato que engendra la Sociedad Anónima. Esto determina que el contrato, al tener la especie de ser una sociedad anónima, tiene la naturaleza de mercantil y constituirá un acto que debe calificarse de comercio.

Este planteamiento en la práctica arroja consecuencias completamente diversas a las derivadas de la categórica decisión que comentamos más arriba fundada en que una sociedad anónima por su naturaleza mercantil siempre estará afecta al pago de patente municipal. Como efecto de la distinción formulada en la prevención resulta que, otra cosa distinta es la actividad que como persona jurídica tenga la sociedad para ejercer derechos y contraer obligaciones derivadas del giro previsto en sus estatutos, como quiera que si el negocio resulta que es civil, no tendría por qué admitirse que se encuadre en una actividad mercantil. Así sería necesario indagar en el giro social y en la actividad específica que como sujeto desarrolla la persona jurídica para luego determinar si se corresponden con los supuestos fácticos de los artículos 23 y 24 de la Ley de Rentas Municipales.

12 El abogado integrante, pese a su prevención concurre al fallo y no es disidente por cuanto, consideró que el giro declarado de la SA y tenido como hecho de la causa, no significa que se agote su finalidad en obtener solamente una rentabilidad de las mismas, sino que se advierte que se añade a estos objetivos otros que son de carácter mercantil, de lo cual se desprende que su giro no es exclusivamente de carácter civil sino que además se incluye en el mismo otras actividades que son mercantiles y por consiguiente, son estas las que le dan al giro el significado de ser mercantiles y a la sociedad la condición de ejercer actos de comercio, en el entendido que efectivamente los ejecute.

13 Esta distinción nace de la conceptualización general de sociedad que hace el Código Civil en su artículo 2053 ubicado dentro del libro IV De las Obligaciones en general y de los Contratos. 
El fundamento de ésta idea y distinción reside en la propia forma como la norma hace la atribución, señala al respecto el abogado integrante: Desde luego, la ley alude a que la sociedad sea mercantil y no a que sea comerciante, de lo que ha de inferirse que la comerciabilidad que consagra la ley se refiere al contrato y no a la índole de la persona jurídica que la sociedad entraña. De ahí que para determinar si efectivamente ejerce el comercio, habrá que estarse a las actividades que abraza el giro para el cual se ha constituido.

A partir de ahí, continua, Por consiguiente, para darle a la sociedad la condición de ejercer el comercio, ha de atenderse a la actividad que persigue y no habrá que estarse a la naturaleza del contrato del cual emana la sociedad, porque siempre será mercantil. Esclarecido que por mercantil que sea el contrato no significa que debe atribuírsele la índole de comerciante a la persona jurídica que la sociedad encarna, para estar en condiciones de reputar si en buenas cuentas ejerce o no el comercio, con independencia del contrato del cual ella emana, habrá de estarse al giro para el cual se ha constituido la sociedad. ${ }^{14}$

\section{Comentarios Finales}

El fallo y la prevención que brevemente comentamos denotan desde ya la vigencia teórica y práctica de la atribución de mercantilidad formal que la ley 18.046 hace a las Sociedades Anónimas, apartándose con ello del criterio material por objeto que conforme al artículo 2059 del CC constituye la regla general. Hablamos de vigencia teórica por cuanto su significación aún hoy no es uniforme, sino interpretable y, práctica por las consecuencias diversas en asuntos tan frecuentes como la afección al pago de patente municipal.

En el plano teórico se advierten dos interpretaciones jurisprudenciales; una, mayoritaria aún, que concluye que la naturaleza siempre mercantil de la $\mathrm{SA}$ es equivalente a naturaleza siempre comercial de sus actos y actividad.

14 Es pertinente precisar que respecto de la distinción entre sociedades civiles y mercantiles y el significado en relación con los actos ejecutados por ella, se ha enunciado una distinción parecida a la de la prevención del abogado integrante Gómez Balmaceda, en efecto, se ha dicho que la SA tiene naturaleza jurídica dual, por un lado y desde el punto de vista del acto constitutivo es un contrato.... y por otro, desde el punto de vista del sujeto emergente es una persona jurídica, esto es un sujeto de derecho. Hasta aquí el razonamiento es idéntico, sin embargo se concluye de modo diverso pues se señala: ...desde la perspectiva del sujeto de derecho, el que la sociedad sea siempre comercial es definirla como comerciante, pero desde el punto de vista del acto constitutivo sería una acto de comercio de ejecución continuada y, en este sentido, conforme al principio de la accesoriedad mercantilizaría todos los actos que realice. Como se aprecia, la distinción entre el acto y el sujeto no tiene mayor relevancia aquí, en relación con los efectos de la significación de la atribución del carácter mercantil que hace la ley, pues en ambos casos, la mercantilidad tiene efectos absolutos, ya sea para el sujeto a quien convierte en comerciante, ya sea para el contrato, que pasa a ser un acto de comercio. En Ubilla, De las Sociedades, cit. nota n.2, p 16. 
Significación de la atribución de mercantilidad a las sociedades anónimas:

un comentario jurisprudencial.

A partir de dicha interpretación, necesario es concluir en la ampliación de la enumeración de actos de comercio que realiza el artículo $3^{\circ}$ del Código de Comercio, comprendiendo también ahora al contrato de sociedad anónima que sería un acto formal de comercio ${ }^{15}$, ya que cualquiera sea su causa y objeto y las personas que en dicho contrato intervengan, por la sola disposición legal en virtud de la forma, la sociedad anónima sería siempre comercial.

Decimos que se trata de una interpretación jurisprudencial mayoritaria aún, por cuanto, en un caso similar más reciente ${ }^{16}$-lo que reafirma la vigencia del asunto-, esto es, un reclamo de ilegalidad por cobro de patente municipal a una sociedad anónima con giro agrícola, calificado como actividad primaria en la que no media proceso alguno de elaboración de productos, nuevamente más de una interpretación rondo el asunto.

Si bien la decisión de la Corte fue semejante a la anterior, esto es, el rechazo del reclamo por estimarse: Que, por lo demás, la reclamante es una sociedad anónima, la que es siempre mercantil según lo dispone la ley 18.046, de suerte que sus actos son invariablemente actos de comercio por el sólo ministerio de la ley y, por lo mismo, gravados con la patente contemplada en el mencionado artículo 23 de la Ley de Rentas Municipales (considerando quinto), se presenta con mayor nitidez una posición diversa tanto, en la opinión de la Fiscal Judicial como en el voto en contra. La primera estuvo por acoger el reclamo de ilegalidad, basada en que la sociedad en cuestión sólo desarrolla actividades primarias exentas de contribución municipal, alejándose así de la interpretación general; en el voto en contra, por su parte, se señaló que debe aplicarse el tributo a la actividad realmente desarrollada por el pretendido contribuyente y no a las que eventualmente puedan desplegarse, ...Y que sea una sociedad anónima y se la entienda por ello mercantil no es óbice para razonar de una manera distinta, toda vez que lo importante en esta materia, digámoslo una vez más, no es si la sociedad se entiende o no mercantil o si su objeto social comprende actos gravados por la disposición antes señalada, sino que lo que interesa es determinar la real actividad desplegada por la reclamante, no las que puede desarrollar...de suerte que el municipio reclamado no puede pretender cobrar el mencionado tributo sin que demuestre que la mencionada persona jurídica desarrolla alguna actividad gravada.

La otra interpretación que se desprende del fallo comentado propone que la significación

15 Lo mismo podría decirse del contrato o acto de declaración de una sociedad por acciones y del acto constitutivo de una empresa individual de responsabilidad limitada.

16 Sentencia del 07 de enero de 2009, en Causa rol 5168-2008 “Agrícola Santa Rosa del Parque S.A. con I. Municipalidad de Providencia", dictada por la Quinta Sala de la Iltma. Corte de Apelaciones de Santiago, presidida por el Ministro don Juan Cristóbal Mera Muñoz e integrada, además, por la Ministro Suplente señora Gloria Solís Romero y por el Abogado Integrante don Carlos López Dawson. En http:// productos.legalpublishing.cl. 
de la expresión la sociedad anónima es siempre mercantil, hecha por la ley 18.046 no significa que cualquier acto de ella tenga carácter mercantil, pues dicha atribución debe entenderse como vinculante solo al contrato de sociedad, pero no significa que la persona jurídica que surge y que es quien desarrolla actividades, adquiere derechos y contrae obligaciones tenga la condición de comerciante. Si el negocio de la sociedad es por naturaleza civil, dicha naturaleza no se ve alterada, pues por aquel otorgamiento legal no tendría por qué admitirse que se encuadre en una actividad mercantil.

En el plano práctico, las consecuencias de una y otra interpretación ya han sido evidenciadas, la primera interpretación acarrea como consecuencia que una sociedad anónima por su naturaleza mercantil siempre estará afecta al pago de patente municipal y nunca estará en condiciones de eximirse de él, no siendo entonces necesarias la rendición de pruebas sobre la naturaleza de su actividad. Por el contrario, conforme a la segunda interpretación el eventual cobro del tributo estaría condicionado a la demostración previa del carácter de hecho gravado de las actividades desarrolladas por la sociedad con prescindencia de si se trata o no de una Sociedad Anónima.

Reconociendo que el asunto es opinable, parece no ser razonable la extrema extensión de la mercantilidad formal de las sociedades anónimas, al punto de hacerlas incluso sujetos de un tributo sin previa averiguación de la presencia de los supuestos fácticos de los hechos gravados.

\section{Anexo: Corte Suprema, Sentencia de 28 de diciembre de 2008 en autos "Inversiones Integradas S.A. con I. Municipalidad de Providencia}

Santiago, veinticuatro de diciembre de dos mil ocho.

Vistos:

En estos autos ingreso Corte $\mathrm{N}^{\circ} 6799$ 07, sobre reclamo de ilegalidad, caratulados "Inversiones Integradas S.A. con I. Municipalidad de Providencia , por sentencia de la Corte de Apelaciones de Santiago, de veintiocho de septiembre de dos mil siete, que está escrita a fojas 81 , se rechazó el reclamo.

Contra esta decisión la parte reclamante dedujo recurso de casación en el fondo para cuyo conocimiento se ha ordenado traer estos autos en relación.

Considerando:

Primero: Que por el recurso se denuncian infringidos los artículos 23 y 24 del decreto ley $\mathrm{N}^{\mathrm{o}} 3.063$ Ley de Rentas Municipales; el artículo $2^{\circ}$ de la Ley de Bases Generales de la Administración del Estado; los artículos $6^{\circ}, 7^{\circ}$ y $19 \mathrm{~N}^{\circ}$ 2, 20, 24 y 26 y los artículos $32 \mathrm{~N}^{\circ} 6,63$ 
$\mathrm{N}^{\mathrm{o}} 14$ y 65 , inciso cuarto, $\mathrm{N}^{\mathrm{o}} 1$, todos de la Carta Fundamental;

Segundo: Que respecto de los errores de derecho que adolece el fallo impugnado, el recurrente explica que, en primer lugar, se ha incurrido en una errónea interpretación de los artículos 23 y 24 de la Ley sobre Rentas Municipales, porque las inversiones pasivas no pueden ser consideradas como actividades terciarias para el efecto de gravarlas con patente municipal. Aduce que el fallo pretende darle a las actividades desarrolladas por su parte el carácter de comerciales, calificándolas de terciarias por el solo hecho que ella sea una sociedad anónima, independientemente a que las actividades se ejerzan o no;

Tercero: Que, agrega, las actividades comerciales de toda sociedad deben enmarcarse dentro del giro acordado por los socios en el contrato de sociedad, el cual, en el caso de Inversiones Integradas S.A. se encuentra limitado sólo al rubro de inversiones (pasivas), sin que las actividades convenidas puedan derivarse a otro tipo de actividad primaria, secundaria o de servicios a terceros, como los descritos en la Ley de la Renta y su normativa complementaria;

Cuarto: Que, además, sostiene que la realización de las actividades relativas al giro han sido de carácter privado o civil, es decir, inversiones pasivas, que son aquéllas que se realizan sin proyección al público o prestando servicios de inversión por los cuales percibe una determinada comisión;

Quinto: Que, congruente con lo anterior y a fin de demostrar la naturaleza de su actividad, señala que la sociedad Inversiones Integradas S.A. declaró y registró ante el Servicio de Impuestos Internos el giro de "Sociedad de Inversión y rentista de capitales y que no ha timbrado ante ese organismo fiscalizador ningún tipo de documento tributario, esto es, facturas o boletas y siempre ha declarado "sin movimiento";

Sexto: Que, en seguida, se sostiene que la sentencia vulnera los aludidos preceptos constitucionales contraviniendo formalmente en un caso lo dispuesto por el artículo $19 \mathrm{~N}^{\mathrm{o}} 20$ al establecer un impuesto al patrimonio y no a las rentas; en otro, efectuando una errónea interpretación del principio de igualdad ante la ley que consagra el artículo $19 \mathrm{~N}^{\circ} 2$ y No 20 ; en un tercer caso, contraviniendo formalmente el artículo $19 \mathrm{~N}^{\circ} 24$, y por último, interpretando equivocadamente los artículos $6^{\circ}$ y $7^{\circ}$ de dicho Estatuto Político;

Séptimo: Que la infracción se produce, según señala el recurrente, porque el fallo pretende establecer la aplicación del consabido impuesto municipal a toda sociedad anónima por el solo hecho que por su constitución la sociedad se considera siempre mercantil y sin que resulte relevante si desarrolla actividades que generan renta o no, calificándolas de terciarias, lo que pugna con las normas constitucionales ya que se está estableciendo un tributo en relación a los haberes y no a las rentas, lo que afecta el principio de igualdad ante la ley, porque respecto de 
la reclamante se hace una discriminación arbitraria que conculca al derecho de propiedad además, por cuanto lo decidido importa una exacción ilegal de recursos;

Octavo: Que, por último, aduce que se vulneran los artículos $6^{\circ}$ y $7^{\circ}$ del Estatuto Político porque el ente edilicio, a través del pronunciamiento que se viene impugnando (sic) pretende que una persona jurídica quede afecta a un impuesto sin que haya incurrido en el hecho gravado que hace exigible el desembolso, acción que está fuera de su potestad y sería nula;

Noveno: Que son hechos de la causa los siguientes:

1) Que la sociedad tiene por objeto social: a. la realización de toda clase de inversiones mobiliarias, para lo cual podrá comprar y vender acciones, valores mobiliarios, efectos de comercio, bonos o debentures, a cualquier título y en cualquier forma; b. la realización de toda clase de inversiones inmobiliarias, para lo cual podrá comprar, vender, explotar, construir, lotear, a cualquier título y en cualquier forma, toda clase de inmuebles, sean éstos urbanos o rurales, de aptitud agrícola, forestal u otra; y, c. la participación en empresas y sociedades de cualquier naturaleza, cuya actividad principal diga relación con el giro enunciado en las letras precedentes, para lo cual podrá comprar, vender acciones de sociedades anónimas y constituir, modificar, transformar, fusionar y disolver sociedades;

2) Que la empresa recurrente tiene la naturaleza jurídica de sociedad anónima;

Décimo: Que sobre la base de esos hechos los jueces del fondo concluyeron que, habida consideración a lo dispuesto en el artículo $1^{\circ}$, inciso segundo, de la Ley $\mathrm{N}^{\circ} 18.046$, que dispone que la sociedad anónima es siempre mercantil, aún cuando se forme para la realización de negocios de carácter civil, debe ser considerada comerciante para todos los efectos legales. Así, en relación con los actos y contratos que esa sociedad celebre o en que intervenga, al igual que con aquellos vinculados con el surgimiento de la misma, deben considerarse "actos de comercio", por aplicación del principio de la accesoriedad. De este modo, encontrándose gravado el ejercicio del comercio resulta procedente el pago de la contribución municipal en cuestión;

Undécimo: Que al decidir como hicieron los sentenciadores no incurrieron en error de derecho; por el contrario, han dado correcta aplicación a las normas que se dicen infringidas, como se pasa a demostrar;

Duodécimo: Que primero resulta conveniente consignar que el artículo 23 de la denominada Ley de Rentas Municipales, dispone textualmente que: "El ejercicio de toda profesión, oficio, industria, comercio, arte o cualquier otra actividad lucrativa secundaria o terciaria, sea cual fuere su naturaleza o denominación, está sujeta a una contribución de patente municipal, con arreglo a las disposiciones de la presente ley. El siguiente inciso se refiere a las actividades primarias o extractivas, las que grava con esta tributación municipal, en los casos de explotación en que medie algún proceso de elaboración de productos; 
Significación de la atribución de mercantilidad a las sociedades anónimas:

un comentario jurisprudencial.

Decimotercero: Que, por su parte, el artículo 24 del mismo texto de ley estatuye que: "La patente grava la actividad que se ejerce por un mismo contribuyente, en su local, oficina, establecimiento, kiosco o lugar determinado con prescindencia de la clase o número de giros o rubros distintos que comprenda, luego establece la forma de cálculo del tributo;

Decimocuarto: Que como se dejó establecido por la sentencia impugnada, la empresa que recurre tiene la naturaleza jurídica de sociedad anónima, lo que reviste trascendencia para resolver el asunto, toda vez que de conformidad con lo dispuesto por el inciso segundo del artículo $1^{\circ}$ de la ley $\mathrm{N}^{\circ} 18.046$, en relación con el artículo 2.064 del Código Civil: "La sociedad anónima es siempre mercantil aun cuando se forme para la realización de negocios de carácter civil. De ahí que, encontrándose entre otras actividades gravadas con patente municipal el ejercicio del comercio, de tal modo que una sociedad anónima por su naturaleza mercantil siempre estará afecta al pago del tributo quiere decir entonces, que la reclamante nunca ha estado en condiciones de eximirse de dicho tributo, como lo han decidido los jueces del fondo;

Decimoquinto: Que, en consecuencia, al no haberse demostrado los errores de derecho en que se funda el recurso, éste debe ser desestimado en todas sus partes.

Por estas consideraciones y de conformidad, además, con lo dispuesto en los artículos 764, 767 y 805 del Código de Procedimiento Civil, se declara que se rechaza el recurso de casación en el fondo interpuesto en lo principal de la presentación de fojas 188, en contra de la sentencia de la Corte de Apelaciones de Santiago, de veintiocho de septiembre de dos mil siete, que está escrita a fojas 181 .

Se deja constancia que el Abogado Integrante señor Gómez concurre al fallo con la prevención que indica:

Que la sola circunstancia que una sociedad anónima esté constituida como tal y que por lo mismo deba reputarse que sea mercantil no significa que tenga la condición de ejercer el comercio y que por ende sea comerciante, si se considera que la mercantilizad mira al contrato y no alcanza a la persona jurídica que se forma con el contrato y que tiene por finalidad la de explotar el giro para el cual se ha creado la sociedad.

En efecto, en estricto derecho que la sociedad anónima revista el carácter de ser mercantil, quiere decir que es comercial en cuanto a la índole que tiene el contrato que engendra la Sociedad Anónima. Esto determina que el contrato, al tener la especie de ser una sociedad anónima, tiene la naturaleza de mercantil y constituirá un acto que debe calificarse de comercio. Sin embargo, otra cosa distinta es la actividad que como persona jurídica tenga la sociedad para ejercer derechos y contraer obligaciones derivadas del giro previsto en sus estatutos, como quiera que si el negocio resulta que es civil, no tendría por qué admitirse que se encuadre en una actividad mercantil. 
Desde luego, la ley alude a que la sociedad sea mercantil y no a que sea comerciante, de lo que ha de inferirse que la comerciabilidad que consagra la ley se refiere al contrato y no a la índole de la persona jurídica que la sociedad entraña. De ahí que para determinar si efectivamente ejerce el comercio, habrá que estarse a las actividades que abraza el giro para el cual se ha constituido.

Por consiguiente, para darle a la sociedad la condición de ejercer el comercio, ha de atenderse a la actividad que persigue y no habrá que estarse a la naturaleza del contrato del cual emana la sociedad, porque siempre será mercantil.

Esclarecido que por mercantil que sea el contrato no significa que debe atribuírsele la índole de comerciante a la persona jurídica que la sociedad encarna, para estar en condiciones de reputar si en buenas cuentas ejerce o no el comercio, con independencia del contrato del cual ella emana, habrá de estarse al giro para el cual se ha constituido la sociedad.

De acuerdo al $\mathrm{N}^{\circ} 1$, letras a), b) y c) del motivo noveno, se ha establecido como hechos de la causa, conforme al objetivo social que se describe en el presente fallo, que ha de considerarse que si bien su giro es realizar todo tipo de inversiones, sea de carácter mobiliario o inmobiliario, así como ha de llevarlas a cabo a través de su participación en sociedades de cualquier naturaleza, no significa que se agote su finalidad en obtener solamente una rentabilidad de las mismas, si se advierte que se añade a estos objetivos otros que son de carácter mercantil, de lo cual se desprende que su giro no es exclusivamente de carácter civil sino que además se incluye en el mismo otras actividades que son mercantiles y por consiguiente, son estas las que le dan al giro el significado de ser mercantiles y a la sociedad la condición de ejercer actos de comercio, en el entendido que efectivamente los ejecute.

Regístrese y devuélvase.

Redacción a cargo del Abogado Integrante señor Rafael Gómez Balmaceda.

Pronunciado por la Tercera Sala, integrada por los Ministros señores Adalis Oyarzún, Héctor Carreño, Haroldo Brito y los Abogados Integrantes señores Fernando Castro y Rafael Gómez. No firman, no obstante haber estado en la vista de la causa y acuerdo del fallo los Abogados Integrantes señores Castro y Gómez por estar ausente. Santiago, 24 de diciembre de 2008 .

Autorizada por la Secretaria Subrogante de esta Corte señora Carola Herrera B. En Santiago, a veinticuatro de diciembre de dos mil ocho notifiqué por el estado diario la resolución precedente.

Rol No 6.7992007. 